Goldschmidt 2021 Abstract

https://doi.org/10.7185/gold2021.4490

\section{The chemical behaviour of halogens in silicate melts}

\section{RICHARD THOMAS ${ }^{1}$ AND BERNARD J WOOD ${ }^{2}$}

${ }^{1}$ University of Oxford

${ }^{2}$ Earth Sciences, University of Oxford

Presenting Author: richard.thomas@worc.ox.ac.uk

Although the halogens are minor constituents of magmatic and hydrothermal systems, they comprise important components of volcanic gases. On a molar basis, they are twice as effective as $\mathrm{H}_{2} \mathrm{O}$ at suppressing the liquidus temperatures of silicate melts [1]. The aim of this study is to understand the chemical behaviour of halogens in melts by experimentally determining their thermodynamic activities. We used halogen buffers $\mathrm{Ag} / \mathrm{AgCl}, \mathrm{Ag} / \mathrm{AgI}$ and $\mathrm{Ag} / \mathrm{AgBr}$ in which $\mathrm{Ag}$ (as oxide) is virtually insoluble in silicate melt under the conditions of the experiment. The buffer controls the fugacity of the halogen of interest. Experiments were performed at 5-20 Kbar and 1200$1500^{\circ} \mathrm{C}$ in a piston-cylinder apparatus. The effect of oxygen fugacity on $\mathrm{Cl}$ solubility was determined using $\mathrm{Re}-\mathrm{ReO}_{2}$ and $\mathrm{C}$ $\mathrm{CO}_{2}$ oxygen buffers.

Our experiments show (1) that chlorine solubility in haplobasalt at $15 \mathrm{Kbar} / 1400^{\circ} \mathrm{C}$ can reach $5 \mathrm{wt} \%$, even at $\mathrm{Cl}_{2}$ fugacities as low as 0.0035 bar. 2) $\mathrm{Cl}$ concentration increases linearly with the square root of chlorine fugacity at fixed $f\left(\mathrm{O}_{2}\right)$, obeying Henry's law up to $\sim 3 \% \mathrm{Cl}$ in the melt. Experiments with Icelandic basalt also showed a Henrian relationship with increasing $\sqrt{ } f\left(\mathrm{Cl}_{2}\right)$ but with lower $\mathrm{Cl}$ solubility at fixed $\mathrm{Cl}$ fugacity than the haplobasalt (Fig.1). (3) $\mathrm{Cl}$ solubility decreases with the fourth root of oxygen fugacity at fixed $\sqrt{ } f\left(\mathrm{Cl}_{2}\right)$. This implies that $\mathrm{Cl}^{-}$replaces $\mathrm{O}^{2-}$ in the silicate framework as follows:

$$
\mathrm{Cl}_{2}{ }^{\text {(gas) }}+\left[\mathrm{O}^{2-}\right]^{(\text {melt })}=2\left[\mathrm{Cl}^{-}\right]^{(\text {melt })}+1 / 2 \mathrm{O}_{2}{ }^{\text {(gas) }}
$$

For an Icelandic basalt with $9 \mathrm{wt} \% \mathrm{FeO}$, the $\mathrm{Cl}$ content in $\mathrm{wt} \%$ as a function of the different intensive variables can be expressed as:

$$
\begin{aligned}
& \log \mathrm{Cl}_{\text {melt }}= \\
& ((930(70) \mathrm{P}) / \mathrm{T})-0.25 \log \left(f\left(\mathrm{O}_{2}\right)\right)+0.5 \log \left(f\left(\mathrm{Cl}_{2}\right)\right)
\end{aligned}
$$

From this relationship, we can show that basalts containing the typical concentration range of $0.05-0.5 \mathrm{wt} \% \mathrm{Cl}$ should only begin to degas their chlorine significantly, as $\mathrm{HCl}$, at pressures in the range $0-5 \mathrm{MPa}$ (Fig.2). We also find that $\mathrm{Cl}$ solubility at fixed oxygen and chlorine fugacity depends strongly on bulk composition. $\mathrm{Cl}$ behaviour is similar to that given by Webster [2] in that increasing $\mathrm{CaO}$ and $\mathrm{MgO}$ contents and decreasing $\mathrm{SiO}_{2}$ concentration all lead to increasing $\mathrm{Cl}$ content.

[1] Filiberto, \& Treiman., (2009). Geology, 263, 60-68.

[2] Webster J. D., et. al (2015) Am. Mineral. 100, 522-535.
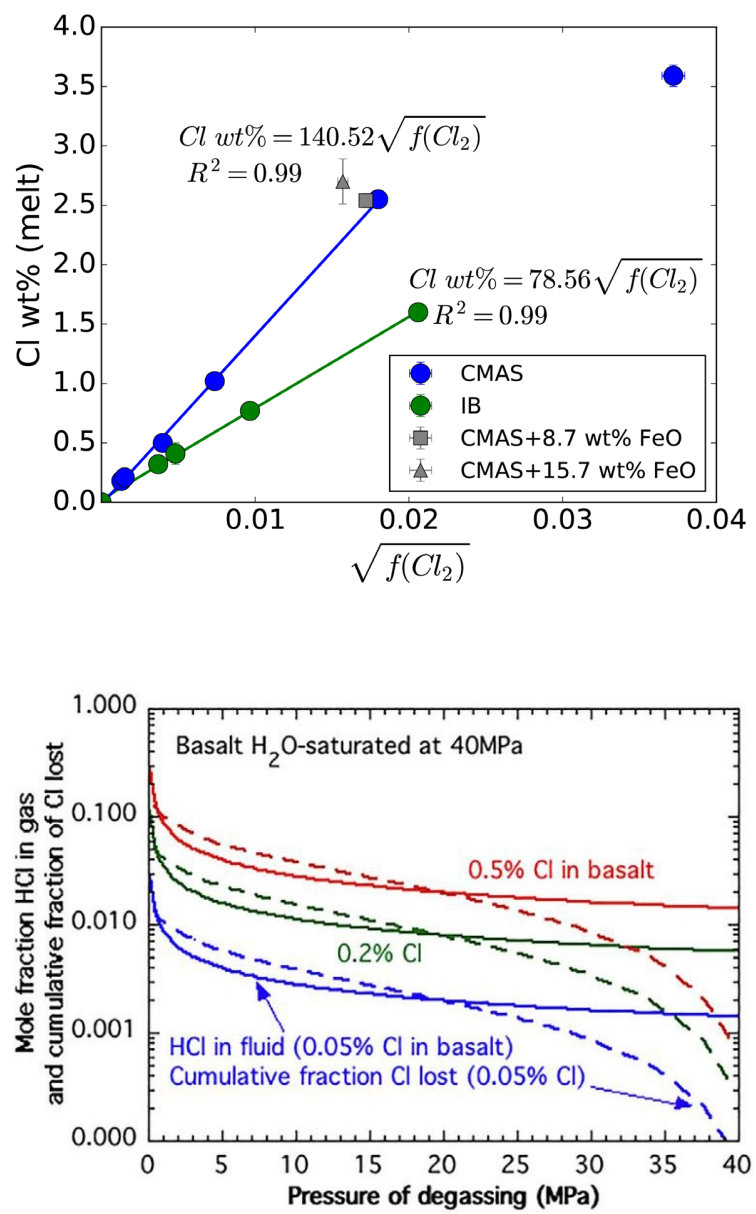